\title{
ATIVIDADES CULTURAIS, ESPORTIVAS E DE LAZER DE ADULTOS
}

Recebido em: 19/09/2012

Aceito em: 25/02/2013

Miria Suzana Burgos ${ }^{1}$
Luciana Tornquist ${ }^{2}$
Debora Tornquist
${ }^{3}$
Cézane Priscila Reuter
Hildegard Hedwig Pohl $^{5}$
Leandro Tibiriçá Burgos $^{6}$
Universidade de Santa Cruz do Sul (UNISC)
Santa Cruz do Sul - RS - Brasil

RESUMO: O objetivo foi identificar as principais atividades culturais, esportivas e de lazer realizadas pelos pais dos escolares do centro, periferia e zona rural do município de Santa Cruz do Sul - RS. Participaram deste estudo transversal 188 adultos. Constatou-se que no sexo masculino o estilo de vida é mais ativo em seu tempo de lazer e que as mães da periferia foram as que se mostraram mais sedentárias. De forma geral, percebemos um predomínio de atividades pouco ativas, sendo preocupante o baixo percentual de pais que declararam realizar algum tipo de atividade física no lazer, pois além de predispostos a fatores de risco, os pais servem de exemplo aos filhos; passando a eles um exemplo indesejável, o sedentarismo.

PALAVRAS CHAVE: Estilo de Vida. Atividades de Lazer. Estilo de Vida Sedentário.

\section{CULTURAL, SPORTS AND LEISURE ACTIVITIES OF ADULTS}

ABSTRACT: The objective of this study was to identify the main cultural, sports and leisure activities carried out by the parents of students living downtown, on the outskirts and in rural areas of the municipality of Santa Cruz do Sul - RS. 188 adults took part of this transversal study. It was realized that for the male gender, the lifestyle is more active in the leisure time and that the mothers living in the outskirts proved to be the most sedentary. In general, we perceived the prevalence of little active activities, and what is reason for concern is the low percentage of parents who declared to carry out some kind of physical activity in their free time, because, in addition to being exposed to risk factors, the parents set an example for the children; which, in the latter case, is undesirable sedentariness.

KEYWORDS: Life Style. Leisure Activities. Sedentary Lifestyle. 


\section{INTRODUÇÃO}

O lazer caracteriza-se pelo tempo em que há ausência de obrigações e deveres profissionais, familiares, religiosos ou outros. Em conseqüência disso, podemos caracterizá-lo como um espaço para atividades lúdicas, prazerosas, vinculadas à satisfação pessoal, atividades que expressam a cultura de um grupo ou sociedade (MELO e ALVES JÚNIOR, 2003). O tempo livre de cada pessoa é ocupado de acordo com suas vivências culturais, hábitos que adquiriu, seu processo de socialização e suas predisposições psíquicas. Desta forma, a maneira como cada pessoa desfruta deste tempo segue a sua estrutura social, cultural, econômica, ideológica e física (SARRIERA et al., 2007).

A redução da prática de atividade física pode estar relacionada com a redução do esforço físico nos processos de trabalho ou nos momentos de lazer, que passaram de atividades com um significativo gasto energético, como em práticas esportivas, para atividades amplamente sedentárias, como o uso do computador e o hábito de assistir televisão (ANJOS, 2001). Peres et al. (2005) afirmam que as atividades de lazer e culturais também podem influenciar o processo saúde/doença. Segundo Azevedo et al. (2008), é importante a prática de atividades físicas, na prevenção e tratamento de diversas doenças como hipertensão, diabetes, cardiopatia isquêmica, depressão, alguns tipos de câncer, entre outras. A inatividade física está entre os quatro principais fatores de risco para as doenças cardiovasculares (MCDOWELL, MCKENNA E NAYLOR, 1997).

Segundo Alvarez (2002), atividade física, alimentação balanceada e o controle do estresse emocional e psicológico, são os principais fatores que devem ser mantidos em equilíbrio para um estilo de vida de qualidade. Qualquer fator que ponha em risco 
um destes componentes irá interferir na qualidade de vida da população, podendo assim diminuir a expectativa de vida. Dentre estes hábitos modificáveis, destaca-se a inatividade física, considerada como um agente de risco primário e comprometedor do bem-estar. Um estilo de vida ativo pode ainda, ter efeitos benéficos na autonomia física e no desenvolvimento das capacidades funcionais durante $\mathrm{o}$ processo de envelhecimento.

Apesar de a maioria das doenças que podem estar associadas ao sedentarismo, só se manifestarem na fase adulta, acredita-se que seu desenvolvimento comece a ocorrer ainda na infância e adolescência. Acredita-se ainda que os hábitos sedentários dos pais possam influenciar na adoção de hábitos sedentários pelos filhos (STRONG et al., 2005). O incentivo familiar à prática esportiva é essencial, e este pode ocorrer de inúmeras maneiras, tanto logística e financeiramente, quanto pelo exemplo passado dentro de casa, onde a relação pais e filhos pode contribuir para o hábito de ser ou não ativo (RAUDSEPP, 2006).

Segundo Pitanga e Lessa (2005), é crescente o número de pessoas que se tornam sedentárias, por terem poucas oportunidades de praticar atividades físicas. Para que ocorra um aumento da prática de atividade física entre a população, fazem-se necessárias mudanças no ambiente físico e social, assim como da influência de políticas públicas, neste meio. Pois, mesmo uma atividade física simples como a caminhada necessita da disponibilidade de locais seguros e atrativos. O hábito da atividade física deve tornar-se uma escolha fácil, consistente e agradável (PRATT, 1999).

Muller (2002) alerta para a responsabilidade dos municípios de promoverem, em suas políticas públicas, a criação de recursos urbanos de recreação e lazer, como parques e áreas verdes, que venham ao encontro das aspirações da população local. 
Entretanto, em estudo, realizado em Santa Cruz do Sul e mais quatro cidades da região, Muller (2001) constatou que os gestores públicos demonstraram desconhecer os princípios, prioridades e estratégias com que deveriam trabalhar, não oferecendo opções diversificadas em conteúdos de lazer à população.

Diante dessas perspectivas, este estudo tem como objetivo identificar as atividades culturais, esportivas e de lazer realizadas por pais de escolares do centro, da periferia e da zona rural, do município de Santa Cruz do Sul - RS.

\section{MÉTODO}

Este estudo transversal faz parte da pesquisa "SAÚDE E ESTILO DE VIDA NA ESCOLA E NA FAMÍLIA: indicadores de saúde de escolares e sua relação com a saúde familiar, no meio urbano e rural de Santa Cruz do Sul”, coordenado por Burgos (2009a). A pesquisa envolveu um total de 1666 escolares investigados, dos quais foram convidados seus pais (pai, mãe ou responsável) para participarem do estudo. Destes, 72 do sexo masculino e 116 do sexo feminino, aderiram ao estudo, totalizando 188 pais, do centro, da periferia e da zona rural do município de Santa Cruz do Sul - RS.

O município de Santa Cruz do Sul é um dos principais núcleos da colonização alemã do Rio Grande do Sul (CARVALHO FILHO e MONASTERIO, 2012). Localizase na região do Vale do Rio Pardo, na encosta inferior do nordeste do estado do Rio Grande do Sul, a 155 km da capital do estado, Porto Alegre. Possui 733,409 km² de área e sua população atual gira em torno de 118.374 habitantes (IBGE, 2012; PMSCS, 2012).

A região na qual o município está inserido representa um importante setor da indústria fumageira no Brasil, representando cerca de $20 \%$ da produção nacional de 
fumo (VARGAS e OLIVEIRA, 2012). Desta forma, o ponto forte da economia da cidade são as inúmeras indústrias fumageiras que ali se instalaram e as plantações de fumo, onde a produção de fumo em folha foi responsável por $60,5 \%$ do valor da produção da agropecuária em 2008 (FOCHEZATTO e GHINIS, 2012). O município ocupa a $9^{\circ}$ colocação no ranking do PIB municipal no estado (2011). Além do fumo, a cidade possui outros ramos fortes em sua economia, como o comércio e serviços. $\mathrm{O}$ segmento comercial é atualmente representado por aproximadamente 2.873 estabelecimentos e mais 1.474 empresas de prestação de serviços. Na totalidade o município tem 354 indústrias e 2.438 profissionais autônomos (PMSCS, 2012).

A cidade possui uma boa infra-estrutura para turismo e eventos, com variadas opções de restaurantes, bares, casas noturnas, cinemas e clubes. Além disso, durante o ano, conta com diversos eventos, em especial a Oktoberfest, que permite mostrar aos turistas e visitantes os costumes germânicos da cidade. Sedia também o maior festival de arte amadora da América Latina, o ENART - Encontro de Arte e Tradição, e conta com o Autódromo Internacional de Santa Cruz do Sul, no Parque de Eventos do Município, que já sediou provas como a Stock Car e a Fórmula Truck (PMSCS, 2012).

A presente pesquisa tem aprovação pelo Comitê de Ética em Pesquisa com Seres Humanos da Universidade de Santa Cruz do Sul (CEP - UNISC - processo 4913/07) e todos os participantes assinaram o termo de consentimento livre e esclarecido antes da sua participação. Na coleta de dados, realizada junto aos pais, foi utilizado o questionário Estilo de Vida, Saúde e Bem-estar, adaptado de Barros e Nahas (2003). Para a aplicação dos questionários, foi feito contato com as escolas para a marcação de reuniões com os pais dos alunos e visitas a algumas residências. Destacamos a grande dificuldade de acesso aos pais e de aderência destes, à pesquisa. A análise estatística dos 
Miria Suzana Burgos, Luciana Tornquist, Débora Tornquist, Cézane Priscila Reuter, Hildegard H. Pohl e Leandro T. Burgos

dados foi realizada no programa SPSS for Windows 18.0, através de análise descritiva (freqüência e percentuais).

\section{RESULTADOS E DISCUSSÃO}

$\mathrm{Na}$ análise das principais atividades realizadas, no tempo livre (lazer) dos pais dos escolares, as com maior evidência, para o sexo masculino (TAB. 1), foram o assistir televisão $(21,7 \%)$, o passear/viajar $(11,1 \%)$, o futebol $(13,7 \%)$ e a caminhada $(10,0 \%)$. $\mathrm{Na}$ análise estratificada por regiões, verificamos na região central, que as atividades mais praticadas pelos pais são o futebol $(25,7 \%)$, a caminhada $(17,1 \%)$ e o passear/viajar (14,3\%). Na periferia, a atividade mais praticada é o assistir TV (26,7\%), o passear/viajar $(12,4 \%)$, e ainda a caminhada (9,5\%). Já, na zona rural, a atividade que mais se destacou foi o assistir televisão $(25,6 \%)$, seguido pelo futebol $(18,6 \%)$.

TABELA 1

Atividades mais realizadas no tempo livre - Masculino (Pais)

\begin{tabular}{|l||c|c|c|c|}
\hline & $\begin{array}{c}\text { Centro } \\
\mathrm{n}(\%)\end{array}$ & $\begin{array}{c}\text { Periferia } \\
\mathrm{n}(\%)\end{array}$ & $\begin{array}{c}\text { Rural } \\
\mathrm{n}(\%)\end{array}$ & $\begin{array}{c}\text { Total } \\
\mathrm{n}(\%)\end{array}$ \\
\hline Caminhada & $6(17,1)$ & $10(9,5)$ & $3(7,0)$ & $19(10,0)$ \\
\hline Ler & $1(2,8)$ & $4(3,8)$ & & $5(2,6)$ \\
\hline Chimarrão & $1(2,8)$ & $8(7,6)$ & $3(7,0)$ & $12(6,3)$ \\
\hline Visitar amigos/ parentes & $1(2,8)$ & $5(4,8)$ & & $4(2,1)$ \\
\hline Pescaria & $2(5,7)$ & $28(26,7)$ & $11(25,6)$ & $6(3,2)$ \\
\hline Assistir TV & & $1(0,9)$ & $2(4,6)$ & $41(21,7)$ \\
\hline Ouvir música & $5(14,3)$ & $13(12,4)$ & $3(7,0)$ & $3(1,6)$ \\
\hline Passear/ Viajar & $1(2,8)$ & $2(1,9)$ & & $21(11,1)$ \\
\hline Corrida & $1(2,8)$ & $1(0,9)$ & & $3(1,6)$ \\
\hline Academia/ Musculação & - & $3(2,9)$ & $1(2,3)$ & $2(1,0)$ \\
\hline Conversar com os amigos & & $1(0,9)$ & $2(4,6)$ & $4(2,1)$ \\
\hline Jogos (Bingos, cartas, bocha) & $1(2,8)$ & $1(0,9)$ & $3(7,0)$ & $3(1,6)$ \\
\hline Vôlei & $9(25,7)$ & $9(8,6)$ & $8(18,6)$ & $5(2,6)$ \\
\hline Futebol & $1(2,8)$ & $2(1,9)$ & $1(2,3)$ & $26(13,7)$ \\
\hline Dormir/ Descansar & $1(2,8)$ & $3(2,9)$ & & $4(2,1)$ \\
\hline Computador/ Internet & $2(5,7)$ & $4(3,8)$ & $1(2,3)$ & $4(2,1)$ \\
\hline Bicicleta & $1(2,8)$ & $1(0,9)$ & $1(2,3)$ & $7(3,7)$ \\
\hline Jardinagem/ Arrumar o pátio & & $2(1,9)$ & $1(2,3)$ & $9(4,8)$ \\
\hline Trabalhar em casa & $2(5,7)$ & $4(3,8)$ & $2(4,6)$ & $3(1,6)$ \\
\hline Outras atividades & $35(100)$ & $105(100)$ & $43(100)$ & $8(4,2)$ \\
\hline TOTAL & & & $189(100)$ \\
\hline
\end{tabular}


Miria Suzana Burgos, Luciana Tornquist, Débora Tornquist, Cézane Priscila Reuter, Hildegard H. Pohl e Leandro T. Burgos

Para o sexo feminino (TAB.), assim como no masculino, o assistir televisão $(24,6 \%)$ é a atividade mais praticada; seguido por ler $(11,4 \%)$, a caminhada $(10,4 \%)$ e tomar chimarrão $(9,4 \%)$. Já, nos resultados por regiões, no centro, a atividade mais praticada pelas mães é a caminhada (17,5\%), leitura (12,5\%) e assistir TV $(12,5 \%)$. Na periferia, a atividade predominante é o assistir TV $(26,3 \%)$, seguido por tomar chimarrão $(12,6 \%)$ e fazer leituras $(9,7 \%)$; na zona rural, a atividade mais praticada, pelas mães, foi o assistir TV (20,5\%), fazer leituras (12,0\%) e a caminhada (10,8\%).

TABELA 2

Atividades mais realizadas no tempo livre - Feminino (Mães)

\begin{tabular}{|l|c|c|c|c|}
\hline & $\begin{array}{c}\text { Centro } \\
\mathrm{n}(\%)\end{array}$ & $\begin{array}{c}\text { Periferia } \\
\mathrm{n}(\%)\end{array}$ & $\begin{array}{c}\text { Rural } \\
\mathrm{n}(\%)\end{array}$ & $\begin{array}{c}\text { Total } \\
\mathrm{n}(\%)\end{array}$ \\
\hline Caminhada & $7(17,5)$ & $13(7,4)$ & $9(10,8)$ & $29(9,7)$ \\
\hline Ler & $5(12,5)$ & $17(9.7)$ & $10(12,0)$ & $32(10,7)$ \\
\hline Chimarrão & - & $22(12,6)$ & $6(7,2)$ & $28(9,4)$ \\
\hline Visitar amigos/ parentes & $2(5,0)$ & $2(1,1)$ & $6(7,2)$ & $10(3,3)$ \\
\hline Tricô/Crochê/ Bordar/ Costurar & $2(5,0)$ & $10(5,7)$ & $4(4,8)$ & $16(5,4)$ \\
\hline Assistir TV & $5(12,5)$ & $46(26,3)$ & $17(20,5)$ & $68(22,8)$ \\
\hline Ouvir música & - & $16(9,1)$ & $3(3,6)$ & $19(6,4)$ \\
\hline Passear/ Viajar & $4(10,0)$ & $14(8,0)$ & $3(3,6)$ & $21(7,0)$ \\
\hline Dançar & $2(5,0)$ & $2(1,1)$ & $1(1,2)$ & $5(1,7)$ \\
\hline Brincar/ Conversar com os filhos & $1(2,5)$ & $7(4,0)$ & $4(4,8)$ & $12(4,0)$ \\
\hline Conversar com os amigos & $1(2,5)$ & $7(4,0)$ & $2(2,4)$ & $10(3,3)$ \\
\hline Jogos (Bingos, cartas, bolão) & - & $3(1,7)$ & $3(3,6)$ & $6(2,0)$ \\
\hline Vôlei/ Futebol & $2(5,0)$ & $1(0,6)$ & $1(1,2)$ & $4(1,3)$ \\
\hline Bicicleta & $4(10,0)$ & $3(1,7)$ & $7(8,5)$ & $14(4,7)$ \\
\hline Jardinagem/ Arrumar o pátio & - & $3(1,7)$ & $2(2,4)$ & $5(1,7)$ \\
\hline Outras atividades & $5(12,5)$ & $9(5,2)$ & $5(6,0)$ & $19(6,4)$ \\
\hline TOTAL & $40(100)$ & $175(100)$ & $83(100)$ & $298(100)$ \\
\hline
\end{tabular}

Podemos constatar, através das atividades de lazer citadas (TAB. 1 e 2), que os pais da região centro demonstraram-se mais ativos no tempo de lazer, do que os pais da periferia e da zona rural, para ambos os sexos, sendo os pais da periferia, os que apresentaram um maior predomínio de atividades de caráter sedentário. 
Em estudo realizado com a população adulta de Goiânia (CUNHA et al. 2008), sobre as atividades mais praticadas no lazer, foram encontradas diferenças na prática de algumas modalidades entre os sexos. Entre os homens, a mais praticada foi à caminhada $(30,9 \%)$, assim como também para as mulheres $(60,6 \%)$, seguido pelo futebol para o sexo masculino $(30,7 \%)$ e musculação para o sexo feminino $(7,4 \%)$. Também corroboram com os nossos resultados, um estudo no Rio de Janeiro (SALLES-COSTA et al. 2003), que verificou que a caminhada foi a atividade mais praticada entre homens e mulheres. Destacaram-se ainda, o elevado percentual da prática de futebol entre homens e da ginástica entre as mulheres. Pode-se destacar também que a prática de futebol, corrida, tênis, vôlei, lutas e musculação foram mais prevalentes entre os homens e a, prática de caminhada, ginástica, dança e de hidroginástica, entre as mulheres. Outro estudo realizado também no Rio de Janeiro (OLIVEIRA, 2000), assemelha-se aos demais, onde a principal atividade destacada foi a caminhada. Além desta, também foram citados a corrida, a musculação, o futebol e a ginástica. É importante destacar que os estudos citados, diferem um pouco do nosso estudo, considerando que esses levam em conta apenas atividades físicas/ esportivas e o atual estudo, engloba toda e qualquer atividade praticada no tempo livre.

Pode-se destacar também, que os pais dos escolares possuem um estilo de vida mais ativo que as mães, sendo que mães da periferia demonstraram serem as que praticam um maior número de atividades sedentárias, não tendo nenhuma atividade de caráter ativo entre as mais citadas (TAB. 1 e 2). Semelhantemente, em estudo realizado em Goiânia (CUNHA et al. 2008), constatou-se que nas atividades físicas de lazer, os homens apresentaram um estilo de vida mais ativo $(33,1 \%)$ do que as mulheres $(20,7 \%)$. De mesmo modo, em estudo de Salles-Costa et al.(2003), realizado no estado do Rio de 
Janeiro, 40,8\% das mulheres da população de estudo referiram alguma prática de exercício no tempo destinado ao lazer e cerca de 52\% dos homens. Em estudo realizado em Pelotas-RS (SILVA et al., 2008), também foram encontrados níveis de atividade física significativamente superiores para os homens $(37,8 \%)$ em relação às mulheres $(24,4 \%)$, sendo que, da população total, apenas 30,2\% obtiveram os índices de prática recomendados. Em estudo em Pernambuco (ALVES et al., 2005) não houve diferença significativa entre os gêneros para a prática de atividades físicas de lazer, sendo esta referida por $76,8 \%$ dos homens e $78,1 \%$ das mulheres.

Estudos de Martins e Santos (2004) mostram que indivíduos que não realizam atividade física regularmente, possuem resultados mais insatisfatórios nos componentes de composição corporal, do que aqueles que possuem uma prática regrada. Este mesmo estudo mostrou também que, independentemente do tipo de atividade física realizada, os indivíduos que a praticam de forma regular, tendem a ter melhor qualidade energética e menor consumo energético. Estudos de Karnoven (1996) mostraram uma forte associação positiva entre a atividade física e a capacidade para o trabalho, o estilo de vida e o bem estar.

$\mathrm{Na}$ TAB. 3, são analisadas as atividades culturais, esportivas e de lazer realizadas, diariamente, em casa. O assistir TV é atividade mais praticada, com apenas 3,4\% das mães declarando não a realizar e com 100\% dos pais, declarando realizá-la. Tanto no centro, como na periferia e na zona rural, o predomínio do tempo ocupado para assistir TV é de até 2 horas por dia. É possível percebermos também, que há um predomínio de atividades sedentárias, como ouvir música e conversar com os amigos, além do assistir TV. Em oposição a estes, podemos destacar as tarefas domésticas, principalmente, entre as mulheres, com um predomínio de tempo ocupado para estas 
Miria Suzana Burgos, Luciana Tornquist, Débora Tornquist, Cézane Priscila Reuter, Hildegard H. Pohl e Leandro T. Burgos

tarefas de até duas horas por dia, exceto para as mulheres da zona rural, onde o predomínio foi de 2 a 4 horas.

TABELA 3

Atividades diárias culturais, esportivas e de lazer realizadas em casa

\begin{tabular}{|c|c|c|c|c|c|c|c|c|c|}
\hline \multirow[b]{2}{*}{ Modalidade } & & \multicolumn{2}{|c|}{ Centro } & \multicolumn{2}{|c|}{ Periferia } & \multicolumn{2}{|c|}{ Rural } & \multicolumn{2}{|c|}{ Total } \\
\hline & $\begin{array}{c}\text { Horas } \\
\text { Diárias }\end{array}$ & $\begin{array}{c}\text { Pais } \\
\mathrm{n}(\%)\end{array}$ & $\begin{array}{l}\text { Mães } \\
\mathrm{n}(\%)\end{array}$ & $\begin{array}{c}\text { Pais } \\
\mathrm{n}(\%)\end{array}$ & $\begin{array}{l}\text { Mães } \\
\text { n (\%) }\end{array}$ & $\begin{array}{c}\text { Pais } \\
\mathrm{n}(\%)\end{array}$ & $\begin{array}{l}\text { Mães } \\
\mathrm{n}(\%)\end{array}$ & $\begin{array}{l}\text { Pais } \\
\mathrm{n}(\%)\end{array}$ & $\begin{array}{l}\text { Mães } \\
\mathrm{n}(\%)\end{array}$ \\
\hline \multirow{4}{*}{ Ver TV } & Nenhuma & - & $1(6,7)$ & - & $2(3,1)$ & - & $1(2,8)$ & - & $4(3,4)$ \\
\hline & $>0$ até 2 & $8(66,7)$ & $12(80,0)$ & $28(68,3)$ & $27(41,5)$ & $12(70,6)$ & $21(58,3)$ & $48(68,6)$ & $60(51,7)$ \\
\hline & $>2$ até 4 & $2(16,7)$ & $1(6,7)$ & $11(26,8)$ & $28(43,1)$ & $4(23,5)$ & $11(30,6)$ & $17(24,3)$ & $40(34,5)$ \\
\hline & $\geq 4$ & $2(16,7)$ & $1(6,7)$ & $2(4,9)$ & $8(12,3)$ & $1(5,9)$ & $3(8,3)$ & $5(7,1)$ & $12(10,3)$ \\
\hline \multirow{4}{*}{$\begin{array}{c}\text { Leituras de } \\
\text { lazer }\end{array}$} & Nenhuma & $7(58,3)$ & $4(26,7)$ & $18(43,9)$ & $32(49,2)$ & $9(52,9)$ & $15(41,7)$ & $34(48,6)$ & $51(44)$ \\
\hline & $>0$ até 2 & $5(41,7)$ & $11(73,3)$ & $22(53,7)$ & $33(50,8)$ & $8(47,1)$ & $20(55,6)$ & $35(50,0)$ & $64(55,2)$ \\
\hline & $>2$ até 4 & - & - & $1(2,4)$ & - & - & $1(2,8)$ & $1(1,4)$ & $1(0,9)$ \\
\hline & $\geq 4$ & - & - & - & - & - & - & - & - \\
\hline \multirow{4}{*}{$\begin{array}{l}\text { Escutar } \\
\text { Música }\end{array}$} & Nenhuma & $3(25,0)$ & $5(33,3)$ & $6(14,3)$ & $12(18,5)$ & $3(17,6)$ & $6(16,7)$ & $12(16,9)$ & $23(19,8)$ \\
\hline & $>0$ até 2 & $8(66,7)$ & $10(66,7)$ & $23(54,8)$ & $37(56,9)$ & $10(58,8)$ & $23(63,9)$ & $41(57,7)$ & $70(70,3)$ \\
\hline & $>2$ até 4 & $1(8,3)$ & - & $10(23,8)$ & $9(13,8)$ & $2(11,8)$ & $3(8,3)$ & $13(18,3)$ & $12(10,3)$ \\
\hline & $\geq 4$ & - & - & $3(7,1)$ & $7(10,8)$ & $2(11,8)$ & $4(11,1)$ & $5(7,0)$ & $11(9,5)$ \\
\hline \multirow{4}{*}{$\begin{array}{l}\text { Conversar } \\
\text { com amigos }\end{array}$} & Nenhuma & $4(30,8)$ & $6(40,0)$ & $11(26,2)$ & $22(33,8)$ & $2(11,8)$ & $9(25,0)$ & $17(23,6)$ & $37(31,9)$ \\
\hline & $>0$ até 2 & $9(69,2)$ & $7(46,7)$ & $24(57,1)$ & $31(47,7)$ & $11(64,7)$ & $22(61,1)$ & $44(61,1)$ & $60(51,7)$ \\
\hline & $>2$ até 4 & - & $1(6,7)$ & $6(14,3)$ & $6(9,2)$ & $2(11,8)$ & $3(8,3)$ & $8(11,1)$ & $10(8,6)$ \\
\hline & $\geq 4$ & - & $1(6,7)$ & $1(2,4)$ & $6(9,2)$ & $2(11,8)$ & $2(5,6)$ & $3(4,2)$ & $9(7,8)$ \\
\hline \multirow{4}{*}{$\begin{array}{c}\text { Realizar } \\
\text { tarefas } \\
\text { domésticas }\end{array}$} & Nenhuma & $4(30,8)$ & $3(20,0)$ & $12(28,6)$ & $5(7,7)$ & $1(5,9)$ & - & $17(23,6)$ & $8(6,9)$ \\
\hline & $>0$ até 2 & $8(61,5)$ & $7(46,7)$ & $26(61,9)$ & $18(27,7)$ & $15(88,2)$ & $9(25,0)$ & $49(68,1)$ & $34(29,3)$ \\
\hline & $>2$ até 4 & $1(7,7)$ & $1(6,7)$ & $4(9,5)$ & $27(41,5)$ & - & $13(36,1)$ & $5(6,9)$ & $41(35,3)$ \\
\hline & $\geq 4$ & - & $4(26,7)$ & - & $15(23,1)$ & $1(5,9)$ & $14(38,9)$ & $1(1,4)$ & $33(28,4)$ \\
\hline
\end{tabular}

Em estudo realizado no Rio de Janeiro (GOMES, SIQUEIRA e SICHIERI, 2001), a média de horas assistindo TV foi levemente superior, sendo de 3,2 horas diárias para os homens e 3,5 horas para as mulheres. Um levantamento realizado nos Estados Unidos, no ano de 2000 revelou uma média de horas gastas em frente à televisão pela população adulta de mais de 28 horas por semana, em média 4 horas por dia (FOSTER, GORE, WEST, 2006). Estudo realizado na Austrália revelou que mesmo em indivíduos ativos, o hábito de assistir televisão, por mais de duas horas, está significativamente relacionado com o aumento do risco para a obesidade (CAMERON 
et al., 2003). Ching et al. (1996) encontraram um risco para o excesso de peso significativamente maior entre os homens que assistem a mais de 41 horas de televisão por semana. Também, relacionaram o tempo de 21 a 40 horas assistindo TV por semana, durante dois anos, com o risco para excesso de peso, em 44\%. Já, entre um tempo consideravelmente mais baixo (como de 2 a 5 horas por semana) não se obteve esta relação.

Segundo Jeffery (1998), passar mais tempo em frente à televisão pode contribuir para o aumento do peso corporal de diferentes maneiras, seja na diminuição do gasto energético, por se tratar de uma atividade sedentária, ou pela ingestão de alimentos calóricos enquanto assiste-se à televisão. O assistir TV não tem apresentado ligação apenas com o aumento do peso corporal. Estudo realizado com mulheres, nos Estados Unidos, revelou que mesmo níveis semanais baixos de visualização de TV, como de 2 a 5 horas, resultaram em um aumento significativo no risco de obesidade; esta relação foi independente dos níveis de atividade física e/ou ingestão calórica (HU, LI et al., 2003).

Há ainda, estudos que relacionam o tempo em frente à TV, negativamente, com o perfil lipídico e a pressão arterial (JAKES et al., 2003; KRONENBERG et al., 2000), com o metabolismo anormal de glicose (DUNSTAN et al., 2004) e também com sintomas depressivos (SIDNEY et al., 1996). Além disso, nos homens, foram encontradas ligações com a circunferência da cintura (KOH-BANERJEE et al., 2003) e com risco para diabetes (HU et al., 2003). O hábito de assistir TV pode ainda influenciar na distribuição da gordura corporal, no risco cardiovascular, entre outros importantes problemas de saúde (FOSTER, GORE, WEST, 2006). 
Miria Suzana Burgos, Luciana Tornquist, Débora Tornquist, Cézane Priscila Reuter, Hildegard H. Pohl e Leandro T. Burgos

A TAB. 4 nos apresenta as principais atividades culturais, esportivas e de lazer praticadas pelos pais fora de suas casas. Esta nos revela um elevado percentual de pais que não realizam atividades como passear a pé, andar de bicicleta, jogar bola e ainda que não realizam nenhuma outra atividade física. Em todas as regiões, a atividade mais praticada é o conversar com os amigos, com um predomínio de menos de 2 horas.

TABELA 4

Atividades diárias culturais, esportivas e de lazer realizadas fora de casa

\begin{tabular}{|c|c|c|c|c|c|c|c|c|c|}
\hline & & \multicolumn{2}{|c|}{ Centro } & \multicolumn{2}{|c|}{ Periferia } & \multicolumn{2}{|c|}{ Rural } & \multicolumn{2}{|c|}{ Total } \\
\hline Modalidade & $\begin{array}{c}\text { Horas } \\
\text { Diárias }\end{array}$ & $\begin{array}{c}\text { Pais } \\
\mathrm{n}(\%)\end{array}$ & $\begin{array}{l}\text { Mães } \\
\mathrm{n}(\%)\end{array}$ & $\begin{array}{c}\text { Pais } \\
\mathrm{n}(\%)\end{array}$ & $\begin{array}{l}\text { Mães } \\
\text { n (\%) }\end{array}$ & $\begin{array}{l}\text { Pais } \\
\mathrm{n}(\%)\end{array}$ & $\begin{array}{l}\text { Mães } \\
\mathrm{n}(\%)\end{array}$ & $\begin{array}{c}\text { Pais } \\
\mathrm{n}(\%)\end{array}$ & $\begin{array}{l}\text { Mães } \\
\mathrm{n}(\%)\end{array}$ \\
\hline \multirow{4}{*}{$\begin{array}{l}\text { Conversar } \\
\text { com } \\
\text { amigos }\end{array}$} & Nenhuma & $3(23,1)$ & $7(46,7)$ & $11(26,2)$ & $19(29,2)$ & $3(17,6)$ & $7(19,4)$ & $17(23,6)$ & $33(28,4)$ \\
\hline & $>0$ até 2 & $9(69,2)$ & $7(46,7)$ & $23(54,8)$ & $32(49,2)$ & $12(70,6)$ & $25(69,4)$ & $44(61,1)$ & $64(55,2)$ \\
\hline & $>2$ até 4 & $1(7,7)$ & $1(6,7)$ & $7(16,7)$ & $10(15,4)$ & $2(11,8)$ & $4(11,1)$ & $10(13,9)$ & $15(12,9)$ \\
\hline & $\geq 4$ & - & - & $1(2,4)$ & $4(6,2)$ & - & - & $1(1,4)$ & $4(3,4)$ \\
\hline \multirow{4}{*}{ Passear a pé } & Nenhuma & $4(30,8)$ & $8(53,3)$ & $24(57,1)$ & $21(32,3)$ & $7(41,2)$ & $17(47,2)$ & $35(48,6)$ & $46(39,7)$ \\
\hline & $>0$ até 2 & $9(69,2)$ & $7(46,7)$ & $18(42,9)$ & $40(61,5)$ & $10(58,8)$ & $17(47,2)$ & $37(51,4)$ & $64(55,2)$ \\
\hline & $>2$ até 4 & - & - & - & $4(6,2)$ & - & $2(5,6)$ & - & $6(5,2)$ \\
\hline & $\geq 4$ & - & - & - & - & - & - & - & - \\
\hline \multirow{4}{*}{$\begin{array}{l}\text { Passear de } \\
\quad \text { carro }\end{array}$} & Nenhuma & $6(46,2)$ & $11(73,3)$ & $20(47,6)$ & $44(67,7)$ & $6(35,3)$ & $21(58,3)$ & $32(44,4)$ & $76(65,5)$ \\
\hline & $>0$ até 2 & $6(46,2)$ & $4(26,7)$ & $17(40,5)$ & $21(32,3)$ & $11(64,7)$ & $15(41,7)$ & $34(47,2)$ & $40(34,5)$ \\
\hline & $>2$ até 4 & $1(7,7)$ & - & $2(4,8)$ & - & - & - & $3(4,2)$ & - \\
\hline & $\geq 4$ & - & - & $3(7,1)$ & - & - & - & $3(4,2)$ & - \\
\hline \multirow{4}{*}{$\begin{array}{c}\text { Andar de } \\
\text { bicicleta }\end{array}$} & Nenhuma & $10(76,9)$ & $12(80,0)$ & $36(85,7)$ & $61(93,8)$ & $13(76,5)$ & $21(58,3)$ & $59(81,9)$ & $94(81,0)$ \\
\hline & $>0$ até 2 & $3(23,1)$ & $3(20,0)$ & $5(11,9)$ & $3(4,6)$ & $4(23,5)$ & $15(41,7)$ & $12(16,7)$ & $21(18,1)$ \\
\hline & $>2$ até 4 & - & - & $1(2,4)$ & $1(1,5)$ & - & - & $1(1,4)$ & $1(0,9)$ \\
\hline & $\geq 4$ & - & - & - & - & - & - & - & - \\
\hline \multirow{4}{*}{$\begin{array}{c}\text { Jogar } \\
\text { bola }\end{array}$} & Nenhuma & $3(23,1)$ & $13(86,7)$ & $31(73,8)$ & $60(92,3)$ & $9(52,9)$ & $35(97,2)$ & $43(59,7)$ & $108(93,1)$ \\
\hline & $>0$ até 2 & $8(61,5)$ & $2(13,3)$ & $11(26,2)$ & $5(7,7)$ & $7(41,2)$ & $1(2,8)$ & $26(36,1)$ & $8(6,9)$ \\
\hline & $>2$ até 4 & $1(7,7)$ & - & - & - & $1(5,9)$ & - & $2(2,8)$ & - \\
\hline & $\geq 4$ & $1(7,7)$ & - & - & - & - & - & $1(1,4)$ & - \\
\hline \multirow{4}{*}{$\begin{array}{l}\text { Praticar } \\
\text { atividades } \\
\text { físicas }\end{array}$} & Nenhuma & $10(76,9)$ & $12(80,0)$ & $36(85,7)$ & $51(78,5)$ & $14(82,4)$ & $29(80,6)$ & $60(83,3)$ & $92(79,3)$ \\
\hline & $>0$ até 2 & $2(15,4)$ & $3(20,0)$ & $6(14,3)$ & $12(18,5)$ & $3(17,6)$ & $7(19,4)$ & $11(15,3)$ & $22(19,0)$ \\
\hline & $>2$ até 4 & - & - & - & $2(3,1)$ & - & - & - & - \\
\hline & $\geq 4$ & $1(7,7)$ & - & - & - & - & - & $1(1,4)$ & $2(1,7)$ \\
\hline
\end{tabular}

Nas atividades realizadas fora de casa (TAB. 4), observou-se um grande número de pais que declarou não realizar nenhuma atividade física. Resultados semelhantes também foram encontrados em estudo no Rio de Janeiro (OLIVEIRA, 2000), que relatou índices de inatividade física de 55,9\% para os homens e 59,8\% em mulheres. Em outro estudo no Rio de Janeiro (GOMES, SIQUEIRA e SICHIERI, 2001), a 
diferença entre os gêneros foi muito superior, onde, na faixa etária de 21 a 40 anos, os índices de inatividade física foram $56,6 \%$ para os homens e $79,4 \%$ para as mulheres. Em estudo realizado nos EUA (PRATT, MACERA e BLANTON, 1999) foram encontrados índices semelhantes, onde apenas $27,7 \%$ da população declararam praticar atividade física moderada ou vigorosa e $29,2 \%$ da população declarou não realizar qualquer atividade física fora do seu trabalho.

Há, ainda, estudo em São Paulo (MATSUDO et al., 2002) que encontrou índices de total sedentarismo muito baixos, de $9,7 \%$ para homens e $8 \%$ para mulheres, porém entre os sujeitos, desse mesmo estudo, foram considerados ativos $54,5 \%$ dos homens (ativos e muito ativos) e 52,7\% das mulheres (ativos e muito ativos), os demais sujeitos foram classificados como "irregularmente ativos", pois não mantém uma prática constante. $\mathrm{O}$ estudo comparou a prática entre as diferentes regiões do estado, sendo que os índices de sedentarismo, aparentemente, foram menores no litoral $(5,8 \%)$, do que na região metropolitana $(6 \%)$ e tendo, o interior, o índice mais elevado $(9,4 \%)$. Já, em estudo realizado na Carolina do Norte nos EUA (HUSTON et al., 2003), 70,3\% das mulheres e $74 \%$ dos homens relataram a realização de alguma atividade física nas horas de lazer. Neste mesmo estudo, $24 \%$ dos sujeitos do sexo feminino e $27 \%$ do sexo masculino relataram realizar os níveis de atividade física recomendados.

Estudo realizado no estado de São Paulo, com uma população masculina, encontrou índices muito inferiores ao atual estudo (FLORINDO et al., 2004); apenas $6,4 \%$ dos entrevistados relataram a prática de atividade física nos últimos 12 meses nos momentos de lazer. Entretanto, 67,8\% disseram andar a pé e de bicicleta, por um período igual ou superior a 30 minutos por dia. Ainda no estudo de São Paulo, 53,5\% 
dos entrevistados disseram assistir TV, com muita freqüência, no tempo destinado ao lazer.

Uma possível justificativa para os resultados encontrados, com relação ao maior acesso do sexo masculino as atividades físicas de lazer, pode se dar as horas que as mulheres acrescentam a sua jornada de trabalho, com tarefas como cuidar dos filhos e serviços domésticos (AQUINO, 1996; DARIDO, 2004). Ressaltando esta perspectiva, Andrade et al. (2009) afirmam que as possibilidades de lazer das mulheres estão geralmente ligadas ao seu papel de mãe, de esposa, ou de filha, diferentemente dos homens, que têm seu lazer mais voltado ao encontro com os amigos. Afirmam ainda que a mulher rural esta ainda mais associada com a visão de mulher "do lar", do que as mulheres do meio urbano. Este fato é confirmado no presente estudo, onde as mulheres do meio rural demonstraram dedicar um maior número de horas aos serviços domésticos, do que as mães das demais regiões.

Quanto aos locais existentes, no bairro, para a prática de alguma atividade física ou de lazer, os pais dos escolares destacaram o pátio de casa $(27,3 \%)$ e a rua $(19,4 \%)$. Os pais do centro deram maior destaque ao pátio de casa $(22,7 \%)$, a rua $(18,2 \%)$ e o parque/praça $(18,2 \%)$. Os da periferia, também destacaram o pátio de casa $(28,4 \%)$ e a rua $(25,9 \%)$. Já, os pais da região rural destacaram, em sua maioria, o campo ou terreno baldio $(30,5 \%)$, o pátio de casa $(27,8 \%)$ e também o clube esportivo ou recreativo $(22,2 \%)$. Entre as mães os locais mais destacados foram também o pátio de casa $(22,8 \%)$, a rua $(15,3 \%)$ e o parque/praça $(14,4 \%)$. As mães da região central destacaram o parque/praça $(36,7 \%)$, o pátio de casa $(16,7 \%)$ e a rua $(16,7 \%)$; as da periferia, também deram maior destaque ao pátio de casa $(18,2 \%)$ e o parque/praça $(17,3 \%)$; e, as mães da região rural, deram maior destaque ao pátio de casa $(32,0 \%)$ e a rua $(17,3 \%)$. 
Estudo na Carolina do Norte, EUA (HUSTON et al., 2003) relatou que 11,5\% da população não têm acesso a locais para a prática de atividades físicas de lazer; $15,5 \%$ têm acesso apenas a locais ao ar livre e apenas 4,2\% disseram ter acesso a locais fechados e, a grande maioria afirmou possuir acesso, tanto a locais ao ar livre, como ambientes fechados. Já em nosso estudo, os principais locais de destaque são locais ao ar livre, como o pátio de casa, a rua, campo/ terreno baldio, parques e praças.

Em relação aos locais mais utilizados para a prática esportiva e de lazer, os pais dos escolares destacaram o pátio de casa, tanto no centro (pais $22,2 \%$ e mães $21,0 \%$ ), zona rural (37,0\% pais e $45,5 \%$ mães), como também na periferia (pais $34,4 \%$ e mães $21,2 \%)$. Na região do centro, ainda é possível destacar o clube esportivo/ recreativo $(16,7 \%)$ entre os pais dos escolares e o parque/praça $(21 \%)$ entre as mães. Já, na periferia, foi grande o índice de pais $(21,3 \%)$ e mães $(30,0 \%)$ que declararam não utilizar nenhum local. $\mathrm{Na}$ zona rural, destaca-se, entre os pais, o clube esportivo/recreativo $(22,2 \%)$ e entra as mães, o parque/praça $(23,6 \%)$ e a rua $(23,6 \%)$. De forma geral, os locais mais utilizados destacados pelos entrevistados foram o pátio de casa (33,0\% pais e $29,9 \%$ mães) seguido pela opção não utilizo, tanto para os pais $(16,0 \%)$ como para as mães $(22,7 \%)$. Resultados semelhantes foram encontrados no estudo de Huston et al. (2003), realizado nos EUA, onde os locais mais comumente citados são as ruas ou estradas $(41,7 \%)$, seguido da residência do entrevistado $(37,6 \%)$; foram citados ainda ginásios privados $(10,5 \%)$, instalações do local de trabalho $(9,6 \%)$ e parques públicos $(8,6 \%)$.

$\mathrm{Na}$ questão sobre as atividades esportivas e de lazer que gostariam de realizar, mas não realizam, tanto os pais do centro $(44,4 \%)$, como da periferia $(23 \%)$, destacaram o futebol, seguidos pela caminhada $(22,2 \%)$, para os pais do centro e pela academia 
$(21,7 \%)$, pelos pais da periferia. Na zona rural, a caminhada $(28,6 \%)$ foi a atividade mais citada pelos pais. Já, as mães dos escolares do centro demonstraram interesse na prática da dança $(28,6 \%)$ e da natação $(28,6 \%)$, seguido pela caminhada $(21,4 \%)$. As mães da região periférica declararam interesse em freqüentar academia $(25,4 \%)$ e também na prática da natação $(15,2 \%)$. E as mães da zona rural, na sua maioria, optaram pelo vôlei $(25,9 \%)$, seguido pela natação $(14,8 \%)$ e a ginástica $(14,8 \%)$ como atividade que desejariam praticar. De maneira geral, entre as atividades mais citadas pelos entrevistados estão, para o masculino, o futebol $(28,2 \%)$ e a caminhada $(18,0 \%)$; e para o sexo feminino, a academia $(19,0 \%)$ e a natação $(17,0 \%)$.

Entre os motivos pelos quais os pais não praticam as atividades desejadas estão, principalmente, a falta de tempo, tanto para os pais (centro $55,6 \%$, periferia $47,8 \%$ e rural $42,9 \%$ ), como para as mães dos escolares (centro $80 \%$, periferia $34,5 \%$ e rural 43,1\%). Nos motivos citados pelos pais, cabe ainda destacar a ocorrência de algum problema de saúde $(33,3 \%)$, para os sujeitos do sexo masculino do centro e, a falta de lugar para a prática, entre as mães da periferia (19\%) e entre os pais da zona rural $(28,6 \%)$. As mães dos escolares da zona rural destacaram também a falta de oportunidade/ condições $(23,1 \%)$. De forma geral, os principais motivos citados foram a falta de tempo (46,2\% pais e $44,4 \%$ mães), a ocorrência de problemas de saúde para o sexo masculino $(15,4 \%)$, e para o feminino, a falta de oportunidades/condições $(13,1 \%)$ e a falta de lugar para a prática $(13,1 \%)$.

Corroborando com estes resultados, estudos de Francken e Raaij (1981) citam como os principais motivos para a insatisfação com o lazer pessoal, as barreiras internas (como o interesse pessoal e a capacidade) que os impedem de passar mais tempo na prática de algumas atividades de lazer, e também barreiras externas, como tempo, 
dinheiro e as circunstâncias pessoais. Já, em estudo no Rio de Janeiro (OLIVEIRA, 2000) os principais motivos para o impedimento da prática de atividades físicas de lazer, foram a rotina de atividades pessoais $(61,9 \%)$, a falta de ânimo $(43,2)$ e horário de trabalho $(24,8 \%)$.

Estudo de Huston et al. (2003) mostram que pessoas com acesso a locais adequados à atividade física, ou com acesso a ruas calçadas, iluminação e segurança pública têm maior probabilidade de realizar atividades físicas no momento de lazer, inclusive apresentando índices mais próximos aos níveis de atividade física recomendados. Muller (2002) também afirma que os espaços disponíveis influenciam diretamente nas escolhas que as pessoas realizam para suas experiências de lazer. Burgos et al. (2009B) sugerem em seu estudo, que o poder público tome conhecimento dos resultados obtidos nos estudos de lazer realizados, para que possam intervir de uma forma eficaz na melhoria das práticas de lazer oferecidas a população, buscando levar um estilo de vida mais ativo e saudável a estas pessoas, sendo através de espaços físicos, recursos materiais ou humanos.

\section{CONSIDERAÇÕES FINAIS}

Podemos concluir que os pais dos escolares têm um estilo de vida mais ativo quando comparados as mães, sendo que as mães da periferia foram as que demonstraram um perfil de característica mais sedentária, com a prática de atividades como assistir TV, tomar chimarrão e fazer leituras. Os pais da região centro foram os que demonstraram o perfil mais ativo, com a predominância de atividades como o futebol, o passear/viajar e a caminhada. 
Foi possível concluir também, que a grande maioria destes pais gostaria de realizar alguma outra atividade física ou de lazer; entre essas o futebol teve destaque no masculino do centro e da periferia e, a caminhada para o rural. Para as mães do centro, a dança, a academia para as da periferia e o vôlei para as do meio rural. Destacou-se, como o principal motivo para a não realização destas atividades, a falta de tempo.

$\mathrm{Na}$ análise das atividades realizadas dentro e fora de casa, foi possível perceber um predomínio de atividades de caráter sedentário, como olhar televisão, escutar música e conversar com os amigos. Nesta análise, também foram preocupantes os baixos percentuais de pais que declararam realizar atividades como andar de bicicleta, passear a pé, ou ainda, realizar qualquer outra atividade física.

A oferta de programas que estimulam a prática esportiva e de atividade física é comum para a faixa de crianças e adolescentes e, até mesmo programas especializados em atividade física para idosos vêm surgindo, na busca da prevenção e diminuição de doenças. Porém, percebe-se que o restante da população está desassistida, sem grandes incentivos à prática e a adoção de um estilo de vida mais saudável. A escolha para a prática de atividade física deve ser facilitada e estimulada, para tanto é necessário que se disponha à população, locais públicos seguros e atrativos. A formação de grupos para a prática das atividades também nos parece uma válida opção, pois se sabe que atividades praticadas em grupo auxiliam na socialização, permitem aos praticantes conhecer novas pessoas, dando um caráter mais lúdico e prazeroso às atividades, proporcionando assim um maior sentimento de bem-estar.

Faz-se necessária a implantação de programas que incentivem a prática esportiva para a população adulta, visto que são incalculáveis os benefícios que a atividade física 
proporciona, entre eles, a promoção da saúde e a prevenção/ diminuição de risco para muitas enfermidades.

\section{REFERÊNCIAS}

ALVAREZ, B.R. Estilo de vida e hábitos de lazer de trabalhadores, após 2 anos de aplicação de programa de ginástica laboral e saúde. 2002. Dissertação (Doutorado) Programa de Pós-graduação em Engenharia de Produção, Universidade Federal de Santa Catarina, Florianópolis, 2002.

ALVES, J. G. B. et al. Prática de esportes durante a adolescência e atividade física de lazer na vida adulta. Revista Brasileira de Medicina do Esporte, v.11, n.5, p. 291-94, 2005.

ANDRADE, R.J. et al. Relações sociais de gênero no meio rural brasileiro: a mulher camponesa e o lazer no início do século XXI no Brasil. Revista Brasileira de Educação Física e Esporte, São Paulo, v.23, n.1, p.39-49, jan./mar. 2009.

ANJOS, L.A. Obesidade nas sociedades contemporâneas: o papel da dieta e da inatividade física. In: CONGRESSO BRASILEIRO DE ATIVIDADE FÍSICA E SAÚDE, 3, Florianópolis, 2001. Anais... Florianópolis: Universidade Federal de Santa Catarina, 2001.

AQUINO, E.M.L. Gênero, Trabalho e Hipertensão Arterial: Um Estudo de Trabalhadores de Enfermagem em Salvador, Bahia. 1996. Dissertação (Doutorado) Instituto de Saúde Coletiva, Universidade Federal da Bahia, Salvador. 1996.

AZEVEDO, M.R et al. Fatores associados ao sedentarismo no lazer de adultos na coorte de nascimentos de 1982, Pelotas. Revista de Saúde Pública, São Paulo, v. 42, n.2, p.70-77, dez. 2008.

BARROS, M.V.G.; NAHAS, M.V. Medidas da atividade física: teoria e aplicação em diversos grupos populacionais. Londrina: Midiograf, 2003.

BURGOS, M.S. Saúde e estilo de vida na escola e na família: indicadores de saúde de escolares e sua relação com a saúde familiar, no meio urbano e rural de Santa Cruz do Sul (Projeto de Pesquisa). UNISC, Santa Cruz do Sul, 2009 a.

BURGOS, M.S. et al. Estilo de vida: lazer e atividades lúdico-desportivas de escolares de Santa Cruz do Sul. Revista Brasileira de Educação Física e Esporte, São Paulo, v. 23, n.1, p. 77-86, jan./mar 2009b. 
CAMERON, A. J. et al. Overweight and obesity in Australia: the 1999-2000 Australian Diabetes, Obesity and Lifestyle Study. The Medical Journal of Australia, v. 178, p.427- 32, 2003.

CARVALHO FILHO, I.; MONASTERIO, L. Immigration and the origins of regional inequality: Government-sponsored European migration to southern Brazil before World War. Regional Science and Urban Economics, v. 42, p. 794-807, 2012.

CHING, P.L.Y.H. et al. Activity level and risk of overweight in male health professionals. American Journal of Public Health, v.86, n.1, p. 25-30, 1996.

CUNHA, I.C. et al. Fatores associados à prática de atividade física na população adulta de Goiânia: monitoramento por meio de entrevistas telefônicas. Revista Brasileira de Epidemiologia, São Paulo, v.1, n.3, p. 495-504, set. 2008.

DARIDO, S. C. A educação física na escola e o processo de formação dos não praticantes de atividade física. Revista Brasileira de Educação Física e Esporte, São Paulo, v.18, n.1, p.61-80, jan./mar. 2004.

DUNSTAN, D.W. et al. Physical activity and television viewing in relation to risk of undiagnosed abnormal glucose metabolism in adults. Diabetes Care, v.27, p. 2603-09, 2004.

FLORINDO, A. A. et al. Metodologia para a avaliação da atividade física habitual em homens com 50 anos ou mais. Revista de Saúde Pública, v.28, n.2, p.307-14, 2004.

FOCHEZATTO, A.; GHINIS, C.P. Estrutura produtiva agropecuária e desempenho econômico regional: o caso do Rio Grande do Sul, 1996-2008. Revista de Economia e Sociologia Rural, Brasília, v. 50, n. 4, out./dez. 2012.

FOSTER, J.A.; GORE, S.A.; WEST, D.S. Altering TV Viewing Habits: An Unexplored Strategy for Adult Obesity Intervention? American Journal of Health Behavior, v.30, n. 1, p. 3-14, 2006.

FRANCKEN, D.A.; RAAIJ, W.F. Van. Satisfaction with leisure time activities. Journal of Leisure Research, v., p. 337-53, 1981.

GOMES, V.B.; SIQUEIRA, K.S.; SICHIERI, R. Atividade física em uma amostra probabilística da população do Município do Rio de Janeiro. Cadernos de Saúde Pública, v. 17, n. 4, p. 969-76, jul-ago 2001.

HU, et al. Television watching and other sedentary behaviors in relation to risk of obesity and type 2 diabetes mellitus in women. JAMA, v.289, n.14, p.1785-91, 2003.

HUSTON, S.L. et al. Neighborhood Environment, Access to Places for Activity, and Leisure-time Physical Activity in a Diverse North Carolina Population. American Journal of Health Promotion, v.18, n.1, p. 58-69, 2003. 
INSTITUTO BRASILEIRO DE GEOGRAFIA ESTATÍSTICA - IBGE. Censo Demográfico 2010. Disponível em: <www.ibge.gov.br>. Acesso em: 2 abr. 2012.

JAKES, R. W. et al. Television viewing and low participation in vigorous recreation are independently associated with obesity and markers of cardiovascular disease risk: EPIC-Norfolk population-based study. European Journal of Clinical Nutrition, v.57, p. 1089-96, 2003.

JEFFERY, R.W. French S.A. Epidemic obesity in the United States: are fast foods and television viewing contributing? American Journal of Public Health, v.88, p. 277$280,1998$.

KARNOVEN, M. J. Physical activity for a healthy life. Research quarterly for exercise and sport, v.67, n.2, p. 213-5, 1996.

KOH-BANERJEE, P. et al. Prospective study of the association of changes in dietary intake, physical activity, alcohol consumption, and smoking with 9-y gain in waist circumference among 16587 US men. American Journal of Clinical Nutrition, v.78, p. 719-27, 2003.

KRONENBERG, F. et al. Influence of leisure time physical activity and television watching on atherosclerosis risk factors in the NHLBI Family Heart Study. Atherosclerosis, v. 153, p. 433-43, 2000.

MARTINS, F.R.; SANTOS, J.A.R. Atividade física de lazer, alimentação e composição corporal. Revista Brasileira de Educação Física e Esporte, São Paulo, v.18, n.2, p.159-67, abr./jun. 2004

MATSUDO, S.M. et al. Nível de atividade física da população do Estado de São Paulo: análise de acordo com o gênero, idade, nível socioeconômico, distribuição geográfica e de conhecimento. Revista Brasileira de Ciência e Movimento, v.10, n.4, p.41-50, 2002.

MCDOWELL, N.; MCKENNA, J.; NAYLOR, P.J. Factors that influence practice nurses to promote physical activity. British Journal of Sports Medicine, v.31, p.308313, 1997.

MELO, V.A.; ALVES JÚNIOR, E. D. Introdução ao lazer. São Paulo: Manole, 2003.

MÜLLER, A. Espaços e Equipamentos de Lazer e Recreação e as Políticas Públicas. In: .; BURGOS, M.S. (Org.). Coletânea de Textos do Encontro Nacional de Recreação e Lazer - 14 ENAREL. Santa Cruz do Sul: EDUNISC, v. 1, 2002.

Políticas públicas setoriais para a área do lazer nos municípios do Vale do Rio Pardo-RS. In: Encontro Nacional de Recreação e Lazer - ENAREL, 2001, Natal RN. Centro Federal de Educação Tecnológica - CEFET, 2001.

OLIVEIRA, C.C.M. Atividade física de lazer e sua associação com variáveis demográficas e outros hábitos relacionados à saúde em funcionários de banco 
estatal. 2000. Dissertação (Mestrado) - Departamento de epidemiologia e métodos quantitativos em saúde, Escola Nacional de Saúde Pública, Fundação Oswaldo Cruz, Rio de Janeiro.

PERES, F. F. et al. Lazer, esporte e cultura na agenda local: a experiência de promoção da saúde em Manguinhos. Ciência \& Saúde Coletiva, Rio de Janeiro, v.10, n.3, p. 75769, set. 2005.

PITANGA, F.J.G.; LESSA, I. Prevalência e fatores associados ao sedentarismo no lazer em adultos. Cadernos de Saúde Pública, Rio de Janeiro, v. 21, n.3, p. 870-77, mai-jun, 2005.

PRATT, M. Benefits of Lifestyle Activity vs. Structured Exercise. JAMA, v.281, n.4, p.375-76, 1999.

.; MACERA, C.A.; BLANTON, C. Levels of physical activity and inactivity in children and adults in the United States: current evidence and research issues. Medicine \& Science in Sports \& Exercise, v.31, n.11, p. 526-33, 1999.

PMSCS - PREFEITURA MUNICIPAL DE SANTA CRUZ DO SUL. Números de Santa Cruz. Disponível em: < http://www.santacruz.rs.gov.br>. Acesso em: 2 abr. 2012.

RAUDSEPP, L. The relationship between socio-economic status, parental support and adolescent physical activity. Acta Paediatrica, v.95, n.1, p.93-98, 2006.

SALLES-COSTA, R. et al. Gênero e prática de atividade física de lazer. Cadernos de Saúde Pública, Rio de Janeiro, v. 19, Sup. 2, p. 325-33, 2003.

SARRIERA, J.C. et al. Uso do tempo livre por adolescentes de classe popular. Psicologia: Reflexão e Crítica, Porto Alegre, v.20, n.3, p.361-67, 2007.

SIDNEY, S. et al. Television viewing and cardiovascular risk factors in young adults: the CARDIA study. Annals of Epidemiology, v.6, p. 154-59, 1996.

SILVA, I. C. M. et al. Atividade física de pais e filhos: um estudo de base populacional. Revista Brasileira de Educação Física e Esportes, São Paulo, v.22, n.4, p.257-63, out./dez. 2008

STRONG, W. B.; et al. Evidence based physical activity for school-age youth. The Journal of Pediatrics, v.146, n.20, p.732-37, 2005.

VARGAS, M.A.; OLIVEIRA, B.F. Estratégias de diversificação em áreas de cultivo de tabaco no Vale do Rio Pardo: uma análise comparativa. Revista de Economia e Sociologia Rural, Brasília, v.50, n.1, jan./mar. 2012. 
Miria Suzana Burgos, Luciana Tornquist, Débora Tornquist, Cézane Priscila Reuter, Hildegard H. Pohl e Leandro T. Burgos

\section{Endereço dos Autores:}

Miria Suzana Burgos

Rua Ernesto Carlos Iserhard, 537

Bairro Higienópolis - CEP: 96825-040

Santa Cruz do Sul - RS

Endereço Eletrônico: mburgos@unisc.br 